\title{
Corrosive Behavior of ASTM A131 Grade A36 Carbon Steel Exposed in Diesel S10/ Saline Water
}

\author{
Diana Magalhães Frazão ${ }^{a *}{ }^{\oplus}$, Ivanilda Ramos de Melo ${ }^{\circledR}$, Magda Rosângela Santos Vieira ${ }^{a}$,
} Severino Leopoldino Urtiga Filho ${ }^{a}$

${ }^{a}$ Universidade Federal de Pernambuco, Departamento de Engenharia Mecânica, Recife, PE, Brazil

Received: February 22, 2019; Revised: January 6, 2020; Accepted: February 04, 2020

This paper sets out to evaluate the corrosion of ASTM A131 grade A36 carbon steel exposed to a diesel oil S10 / saline water system and the biodegradation of diesel oil S10 to simulate storage, transport and fuel use systems during a period of 30 days. The corrosion process was investigated through electrochemical tests of Open Circuit Potential (OCP), Electrochemical Impedance Spectroscopy (EIS) and Linear Polarization (LP). The morphology of the corrosion products were analyzed by Scanning Electron Microscopy (SEM). The results showed that the presence of saline water in the system containing diesel oil is an aggravating factor which promotes the biodegradation of the fuel and, consequently, aggravates the corrosion process.

Keywords: Corrosion, biodegradation of fuels, diesel/saline water biphasic systems, electrochemical tests.

\section{Introduction}

Diesel oil is a global energy resource mainly used for heating and transportation, such as commercial trucks, construction equipment, all freight locomotives and marine vessels that are powered by diesel engines. In the United States of America (USA), for example, approximately 600 million liters of diesel oil were consumed per day in 2016 and forecasts indicate that consumption will increase by more than 111 million liters / day, by $2040^{1}$. However, severe corrosion processes occur in fuel storage and distribution systems (diesel and / or biodiesel).

On surfaces exposed to external conditions, the corrosion of iron by oxygen from the air occurs more frequently, which is purely an electrochemical process ${ }^{2,3}$. In storage tanks, corrosion and biocorrosion processes occur due to the small amount of water accumulated immediately below the layer of diesel oil and / or biodiesel. This accumulation of water can be from the washing of fuel and biofuel and the condensation of vapors from both. It is important to consider the hygroscopic ability of biodiesel to easily absorb moisture ${ }^{2,3}$. In addition, a limiting factor in the insertion of biodiesel into diesel is the non-uniformity in the raw material composition of the biodiesel provided. This may lead to variations in biofuel processing, storage and transport conditions. According to Kovács et al. ${ }^{3}$, the non-uniformity in the composition difficults the control of the biodiesel quality, especially when it comes to moisture content. Consequently, it promotes the biodegradation process.

The biodegradation of fuel is a major concern for the industrial sector, because in addition to modifying the composition and quality of diesel, it can also make it a very corrosive medium for the metallic materials used in the tanks. This process is closely associated to the accumulation of a layer of water at the bottom of the storage tank. Thus, this accumulation of water contributes to a biodegradation

*e-mail: diana1agatha@gmail.com of diesel oil and biodiesel and, consequently, it promotes corrosion ${ }^{4}$. Since there is no uniformity in the composition of biodiesel in the diesel, the identification of the factors that cause biodegradation of the fuel becomes complex.

Different contaminants in biodiesel storage tanks may be present in the different stages involved in the processing due to a diversified cycle of suppliers ${ }^{3}$. Besides the accumulation of water below the layers of diesel and biodiesel, there is another aggravating factor. In the same way as the transportation of diesel occurs by sea lanes, ships also use many tanks to storage the biofuel (biodiesel). To maintain the stability of the ship, a designed system is required so that the reactor is counterbalanced with sea water. The purpose is to replace the consumed fuel and compensate for the weight loss of the reactor automatically. However, when the reactor is replenished, saline wastewater can remain at the bottom of the tank. Thus, the presence of saline water may cause fuel contamination and corrosion of the tank surface exposed to oil / saline water mixture ${ }^{5}$.

Therefore, the objective of the research is to simulate ship fuel storage tanks to understand the dynamics of the corrosion process. Thus, ASTM A131 G A36 carbon steel was chosen because it is a naval steel commonly used in the manufacture of these tanks. In addition, biodegradation of diesel oil S10 was also evaluated due to saline contamination for a period of 30 days. These studies were performed through electrochemical analysis and scanning electron microscopy.

\section{Materials and Methods}

\subsection{Preparation of the samples}

To evaluate the corrosion process, ASTM A 131 grade A36 carbon steel samples were cut in dimensions of $11.0 \mathrm{~mm}$ x $12.0 \mathrm{~mm} \times 8.0 \mathrm{~mm}$, with an elemental composition (wt.\%) of: $0.25 \mathrm{C}, 0.80-1.20 \mathrm{Mn}, 0.40 \mathrm{Si}, 0.04 \mathrm{P}, 0.05 \mathrm{~S}, 0.20 \mathrm{Cu}$ 
and balance Fe. The samples were welded to a copper wire and embedded with an epoxy resin. Posteriorly, they were abraded with sandpapers 220, 330, 400, 600, 800 and 1200 mesh. Then they were polished with a $3 \mu \mathrm{m}$ and $1 \mu \mathrm{m}$ diamond paste obtaining, in the end, an exposed area of approximately $100 \mathrm{~mm}^{2}$. In order to ensure the $100 \mathrm{~mm}^{2}$ bounded region and to correct embedding process failures it was necessary to delimit the region with a high - adherence adhesive tape. Fig. 1 represents the samples used in the electrochemical tests and their representative diagram.
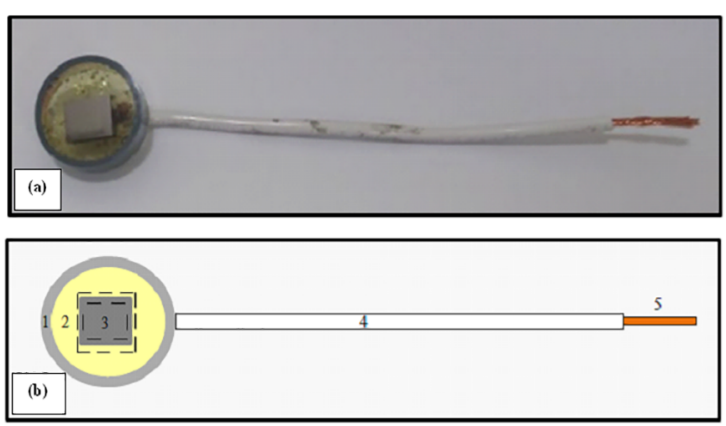

Figure 1. (a) ASTM A131 grade A36 carbon steel sample used for electrochemical tests. (b) Representative diagram: 1 - PVC pipe, 2 - epoxy resin, 3 - delimited area of specimens, 4 - encapsulated copper wire that was welded to metal, 5 - bare copper wire to maintain electrical contact. The dotted region corresponds to the stretch isolated with high adherence tape.

\subsection{Samples immersion studies in diesel S10/ saline water biphasic systems}

Two static immersion studies (without agitation) were performed in a diesel oil S10 / saline water biphasic system in $\mathrm{NaCl} 3.5$ wt.\%. The first study was performed to observe the corrosive action on the metal surface over time. The second study was conducted to observe the biodegradation of the fuel. In the first study (S1), the specimen was immersed directly in saline water. In the second study (S2), the specimen was immersed directly in the oil. Fig. 2 (a, b) shows the immersion systems for the previously described studies.

\subsection{Electrochemical testing}

All electrochemical tests were performed in AUTOLAB Galvanostat/Potentiostat, model PGSTAT $302 \mathrm{~N}$ and controlled by NOVA 1.11 software. A three-electrode electrochemical cell was used: working electrode (sample of approximately 100 $\mathrm{mm}^{2}$ ), reference electrode $\mathrm{Ag} / \mathrm{AgCl}, \mathrm{KCl}$ (sat) and a platinum auxiliary electrode. The conditions of the electrochemical tests for the S1 and S2 studies are detailed.

\subsubsection{Electrochemical tests for the immersion study SI}

ASTM A131 grade A36 carbon steel samples were immersed in the system containing diesel oil S10 / saline water, during 30 days of exposure, and directly exposed to the aqueous phase. The electrochemical impedance spectroscopy

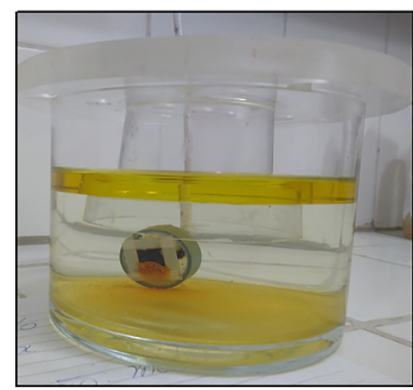

(a) Biph asic immersion system $\mathrm{Sl}$

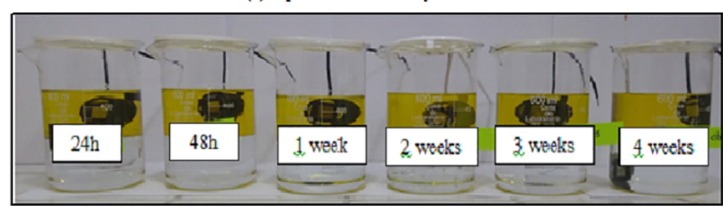

Figure 2. (a) Biphasic immersion system S1, diesel oil S10 / saline water in $\mathrm{NaCl} 3.5$ wt.\%, with sample immersed in aqueous solution; (b) Biphasic immersion system S2, diesel oil S10 / saline water in $\mathrm{NaCl} 3.5$ wt.\%, with sample immersed in diesel oil.

assays were performed during a period of $24 \mathrm{~h}, 48 \mathrm{~h}, 1$ week, 2 weeks, 3 weeks and 4 weeks. The tests were conducted under conditions of stable potential, after initial exposure of $24 \mathrm{~h}$, using a frequency range of $1 \mathrm{mHz}$ to $40 \mathrm{KHz}$ and amplitude of $10 \mathrm{mV}$.

\subsubsection{Electrochemical tests for the immersion study $S 2$}

In the second study, tests of open circuit potential were performed, as well as electrochemical impedance spectroscopy and linear polarization to analyze the resistive behavior of the oil in contact with saline water.

The tests were performed indirectly, in which the samples were immersed in the oil, and after a pre-defined exposure time (24h, 48h, 1 week, 2 weeks, 3 weeks and 4 weeks) they were removed and inserted in $\mathrm{NaCl} 3.5 \mathrm{wt}$ \% \% solution to obtain the electrochemical measurements.

The electrochemical test measurements from study S2 were not performed directly on diesel oil S10, due to the high resistivity of the medium. In addition, there was a limitation on the use of commercial electrodes for analysis directly in oil. According to $\operatorname{Tan}^{6}$ corrosion in highly resistive and heterogeneous media, as is the case under study, is a serious problem that often causes material failure in industrial and civil structures such as corrosion under deposit in pipelines. Corrosion processes in heterogeneous media generally have complex mechanisms, leading to various forms of localized corrosion and crevice corrosion. Also for other researchers, the choice of this method to perform the electrochemical tests was the way found, due to the difficulty in obtaining measurements in a highly resistive medium. Matos ${ }^{7}$ also performed indirect measurements, whose metal samples were separately immersed in fuels and, subsequently, electrochemical tests were performed on cells containing $0.5 \mathrm{~mol} \mathrm{~L}^{-1} \mathrm{NaCl}$ solution. 
Before the execution of electrochemical tests, the samples were immersed in $\mathrm{NaCl} 3.5 \mathrm{wt} . \%$ solution for $17 \mathrm{~h}$ to reach the stabilization potential. As standard analysis, a sample immersed in oil was used, which was immediately removed and immersed in saline solution, to obtain the electrochemical measurements.

Subsequently, the electrochemical impedance spectroscopy test was performed, using a frequency range of $6 \mathrm{mHz}$ at 40 $\mathrm{KHz}$ and amplitude of $10 \mathrm{mV}$.

Linear polarization curves were obtained, applying a potential range of $-0.400 \mathrm{~V}$ to $0.400 \mathrm{~V}$ vs Ag/ $\mathrm{AgCl}$ sat, in relation to the corrosion potential and scanning rate of $0.333 \mathrm{mV} / \mathrm{s}$.

\subsection{Surface characterization}

The surface of the samples exposed in $\mathrm{NaCl} 3.5$ wt.\% solution in study S1 were analyzed by Scanning Electron Microscopy (SEM), TESCAN brand, model MIRA 3. This analysis was performed to identify the morphology present in the film deposited on the substrate surface, that is, possible presence of cells indicating microorganisms and corrosion products. In addition, SEM analyzes were also performed to identify the possible occurrence of localized corrosion. Thus, to remove surface deposits, the corroded samples were subjected to acid pickling in $26 \%(\mathrm{w} / \mathrm{v})$ hydrochloric acid solution for 10 seconds. Then, neutralization was performed by immersion in $10 \%(\mathrm{w} / \mathrm{v}) \mathrm{NaOH}$ solution for 10 seconds and finally the samples were immersed in isopropyl alcohol and then in acetone for 10 seconds, respectively.

\section{Results and Discussion}

\subsection{Electrochemical impedance measurements}

In Fig. 3 (a, b), the Nyquist diagrams and the Bode Phase and Bode Modulus diagrams are presented respectively, after the immersion times of $24 \mathrm{~h}, 48 \mathrm{~h}, 1$ week, 2 weeks, 3 weeks and 4 weeks, obtained in the study S1. These diagrams show the behavior of the corrosion process for ASTM A 131 grade A36 carbon steel exposed to the diesel oil S10 / saltine water ( $\mathrm{NaCl} 3.5$ wt.\%) biphasic system.

As seen in Fig. 3a, there is a tendency of decreasing the diameter of the capacitive arcs over the exposure time in the corrosive medium. This reduction is associated to the occurrence of a corrosion process on the surface of the metal exposed directly to the aqueous phase of the diesel / saline water system. The formation of the semicircles indicates the presence of both resistive and capacitive components, contributing to the variation of the impedance values.

Generally, resistive components may be associated with the deposition of biofilm on the metal surface in addition to corrosion products. These deposits act as a barrier, making it difficult to the electrolyte access to the substrate. In static conditions, as in the case studied, there is the formation and development of a non-compact film that is showing porosity and consequently, favoring the permeation of the electrolyte. The accumulation of charge on the surface, due to this permeation, could promote a capacitive contribution to the system ${ }^{8}$.

The analysis in the Nyquist and Bode Diagrams (Fig. $3 a-b)$ at higher frequency region show very low and close impedance values, indicating that there was little change in the solution resistance value in function of the immersion time. This behavior can be associated with the high conductivity of the medium. However, this high conductivity should not be correlated with a high corrosive action, as in high frequency regions it is not possible to make associations with the nature of the film or deposits formed on the metal surface, which may be soluble or insoluble in the medium.

Fig. $3 \mathrm{~b}$ shows the graphs of Bode Phase and Bode Modulus overlapped. In both graphs, at low frequencies, the behavior of the material was evaluated. As seen in the Bode Modulus graph, there was a decrease in the impedance modulus with increasing electrolyte exposure time.

This behavior may be associated with the morphological nature of the film deposited on the metal surface. Probably the formation of more homogeneous and less porous deposit initially occurred, which made it difficult to the electrolyte to reach the surface. Over time, there was detachmet of deposits causing portions of the surface of the sample to be exposed to the electrolyte once again. Consequently, the deposits of porous layers were continuously formed, thus contributing to the reduction of the impedance modulus of the system ${ }^{9}$.

Fig. 3b, at medium frequencies region, an increase in the value in the phase angle was observed, which can be attributed to the charging of the double electric layer. In addition, the formation of porous layers of corrosion products with consequent surface exposure due to electrolyte permeation, contributes to intensify the performance of the capacitive components of the system. In this region, the angles tend to become higher.

Values close to $90^{\circ}$ allow greater capacitive contribution to the system's impedance modulus. The results show that initially, the permeation by these pores is smaller and it becomes more accentuated as the exposure time increases.

Lopes ${ }^{9}$ analyzed the corrosion processes in carbon steel in the petroleum industry. In his study, comparisons of the corrosive action of the $0.1 \mathrm{M} \mathrm{Na}_{2} \mathrm{SO}_{4}$ solution on the material were conducted, for the periods of 7 and 30 days immersion. He observed that the products initially formed on the metal surface promoted a more effective protection against corrosion, observing, in this case, superior potential values. For the EIS tests, it was observed in the Nyquist digrams, a behavior similar to that found in the present study. There was a reduction of the capacitive arc for higher exposure times to saline solution, indicating that for longer exposure times, the deposits become more susceptible to electrolyte permeation and consequently to corrosive attack. 


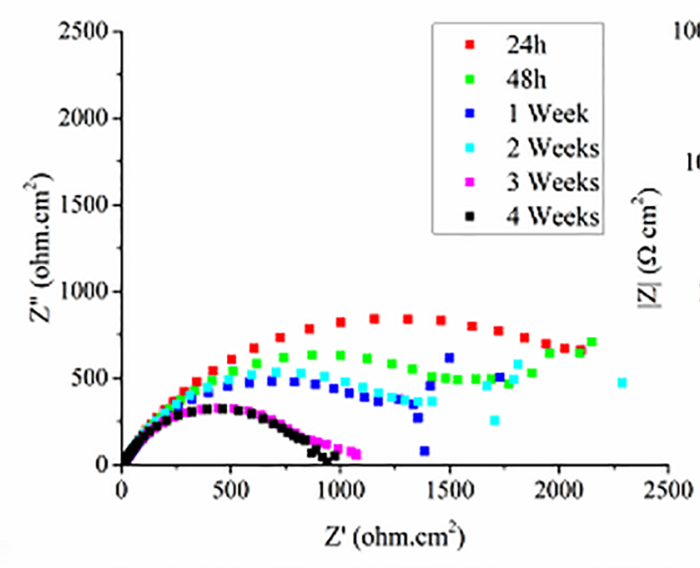

(a) Nyquist diagrams

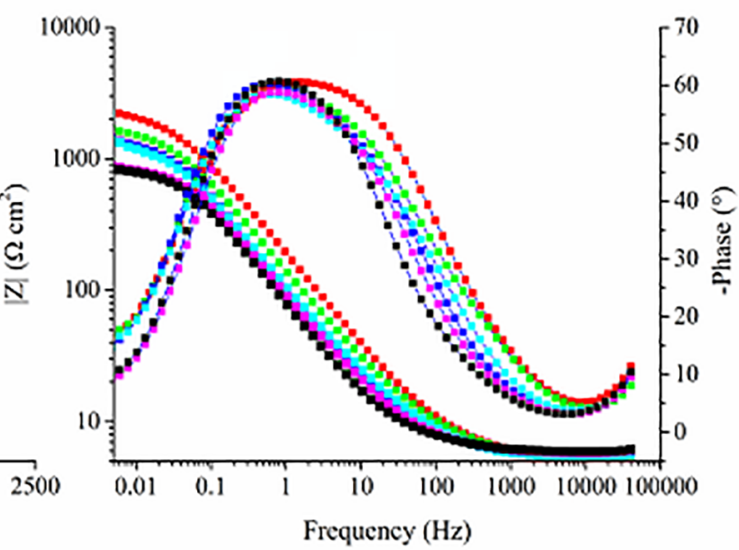

(b) Bode Phase and Bode Modulus diagrams

Figure 3. Study S1: (a) Nyquist diagrams; (b) Bode Phase and Bode Modulus diagrams of ASTM A 131 grade A36 carbon steel immersed in diesel oil $\mathrm{S} 10$ / saline water in $\mathrm{NaCl} 3.5 \mathrm{wt} \%$ as a function of the exposure time.

\subsubsection{Development of the Deposit Formed on the Surface}

Fig. 4 shows photographs of the region of the samples exposed to immersion tests over a period of 30 days. As observed, there is deposit formation with two distinct configurations: the first with a more compact appearance, formed immediately above the substrate (black layer), and the second with a flocculent characteristic, which appears to be more porous and superimposed on the first layer (yellowish layer).

Vieira ${ }^{10}$, when studying the corrosion and biocorrosion processes caused by petroleum industry fluids, observed that these types of systems are complex due to the amount of variables involved. The exposure time may interfere in the formation of the layer, which becomes increasingly thick, in such a way that a detachment can occur, which contributes to the formation of even more porous layers. This mechanism can facilitate the acces of the electrolyte to the substrate and favor the occurence of corrosion process, resulting in smaller capacitive arcs for longer exposure times.

However, when discussing the initial behavior of the immersion process, Zhang and Cheng ${ }^{11}$ also found similar answers in their studies. The initial corrosion process was very intense, due to the aggressiveness of the medium, leading to the formation of a more compact layer. Thus, when this resistive layer was formed, a barrier was established, which made difficult a direct contact between the electrolyte and the substrate. According to the authors, this physical barrier promoted the increase of the resistance to charge transfer. Thus, there was the formation of larger capacitive circles, characteristic of a resistive tendency. This behavior was also observed in this study in the initial immersion process, where the capacitive arcs were higher at $24 \mathrm{~h}$ and $48 \mathrm{~h}$.
According to Tribollet and Orazem ${ }^{12}$ these deposited layers show that the interface between the two films can be considered an equipotential plane, thus allowing the separation of the two deposit parts. The outermost film is much thicker than the innermost film, which is immediately deposited on the surface and has few pores. For a better understanding of the system, it is observed that the innermost film should correspond to the film formed from corrosion due to the preferential dissolution of ferrite, while the outermost film results from the precipitation caused by the elevated concentration of ion in the corrosive medium.

\subsubsection{Surface morphological analysis}

Fig. 5 shows the micrograph of the deposit formed on the surface of the ASTM A131 grade A36 carbon steel after 30 days of immersion in diesel oil S10 / saline water ( $\mathrm{NaCl} 3.5$ wt.\%).

Although the study is not directly related to microbial corrosion, it was possible to observe the presence of microorganisms, probably bacteria in the form of rods, besides the corrosion products formed on the metal surface, as shown in Fig 5 (a, b), respectively. In addition, the presence of saline water accelerated the corrosion process and promoted the formation of localized corrosion on the surface of the sample, which can be observed after the acid pickling process to remove the adhered film, as can be seen in Fig. 5c.

These observations are in agreement with the studies developed by Song et al. ${ }^{2}$, which studied the behavior of microbial corrosion in pipelines and observed that there was severe localized corrosion internally. The morphology of corrosion on the inner wall of the pipeline indicates that localized and generalized corrosion has occurred due to the numerous corrosion wells in the inner wall. According to 

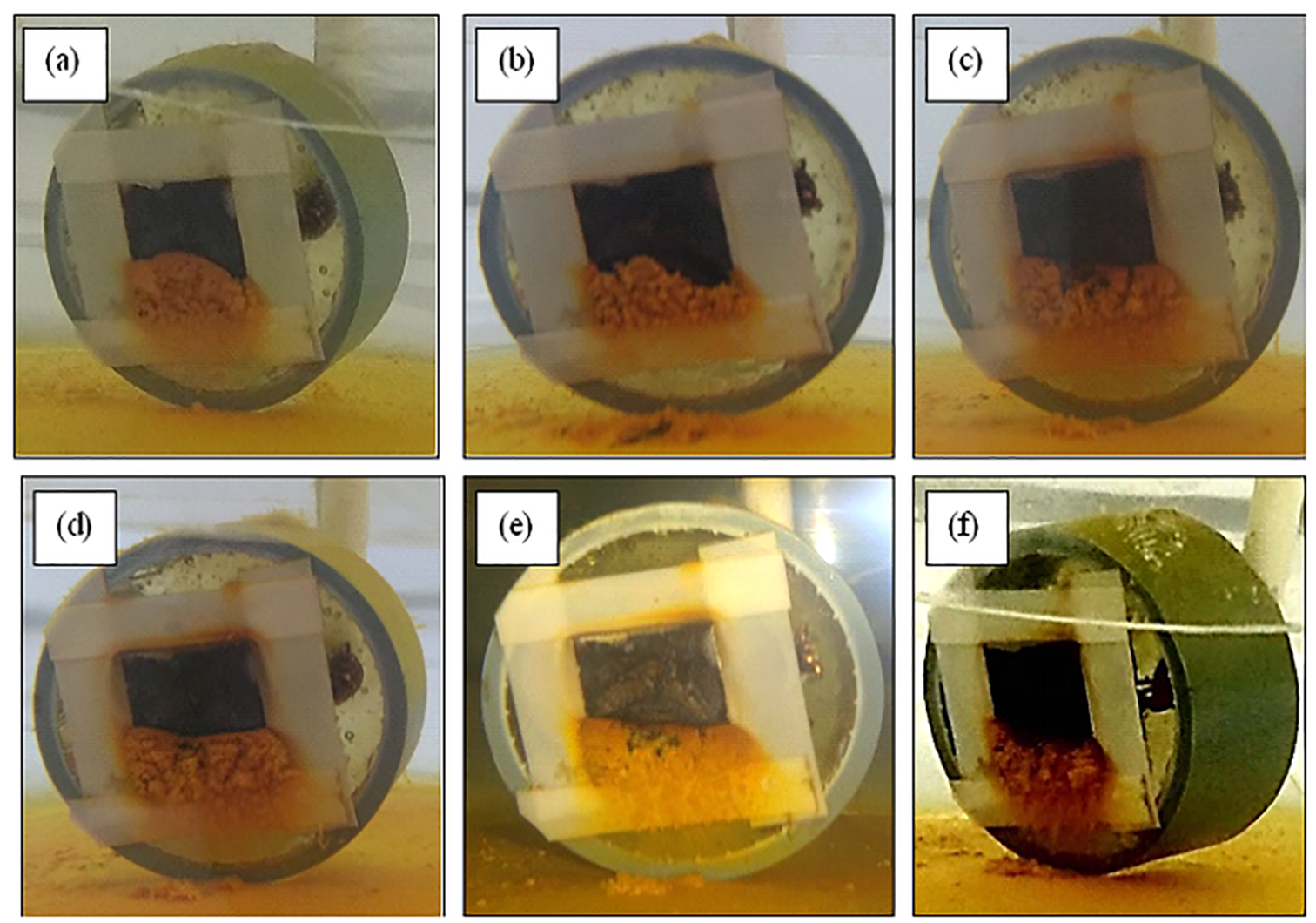

Figure 4. Evolution of the deposit layer on the surface of ASTM A131 grade A36 carbon steel. (a) after 24 hours; (b) after 48h; (c) after 1 week; (d) after 2 weeks; (e) after 3 weeks; (f) after 4 weeks.

Gentil ${ }^{13}$ and Beimeng et al. ${ }^{14}$, these characteristics in the corrosion process can be influenced and accentuated by microorganism induced corrosion (MIC). This MIC can contribute to corrosion caused by direct influence on the speed of reactions, modifications in the resistance of the film formed on the surface, helping in the formation of corrosive media and in the formation of tubers that allow the appearing of differential aeration cells.

According to Maruthamuthu et al. ${ }^{15}$ and Jones and Amy ${ }^{16}$, systems similar to fuel storage tanks or distribution systems such as oil pipelines containing fuel contaminated with water, have an abundance of microorganisms that directly or indirectly increase localized corrosion. The bacteria can oxidize a variety of chemicals present in fuel and use them as sources of nutrients for them to grow.

\subsection{OCP, impedance and polarization measures}

Fig. 6 shows an open circuit potential plot in function of the immersion time for ASTM A131 grade A36 carbon steel exposed in diesel oil S10 contaminated with saline water after 11 hours of potential stabilization. Over time, it was observed that the potential values became more negative, exhibiting a behavior of biodegradation of the fuel. According to Gentil ${ }^{13}$, this behavior may be associated with microbial growth for fuel related deterioration or corrosion. However, it is important to note that the change in open circuit potential values may also be associated with electrode composition variation, with possible oxide formation over time, due to the oil layer biodegradation. The electrode composition is associated with $\mathrm{E}^{\circ}$, changes in the surface may promote variation in OCP values, besides the surface charge. At first, the medium was the same for all measurements, and over time it varied due to changes in oil, leaving electrode composition and charge also as variables. If these measurements are not constant, it can be said that the oil interacts with the surface and this leads to its degradation.

This process of biodegradation may have been influenced by microorganisms, which can use the diesel $\mathrm{S} 10$ as a source of carbon and nutrients for its development ${ }^{4}$.

Initially, the diesel oil S10 would be exempt from the biodegradation process because the fuel is new. Over time, the contamination of the oil through the saline water promoted the biodegradability. The growth and development of microorganisms may have been stimulated by means of chemical substances present in the oil, and can act as a nutritional source, conditioning an environment conducive to microbiological performance. Possibly, in this process, the fuel was losing its efficiency as a film, initially protective, and favoring the passage of the electrolyte until reaching the substrate.

Fig. 7 shows the Nyquist and Bode diagrams in function of immersion time for ASTM A 131 grade A36 carbon steel exposed in diesel oil S10 / saline water in $\mathrm{NaCl} 3.5$ wt.\%. These diagrams correspond to immersion tests after $24 \mathrm{~h}$, 


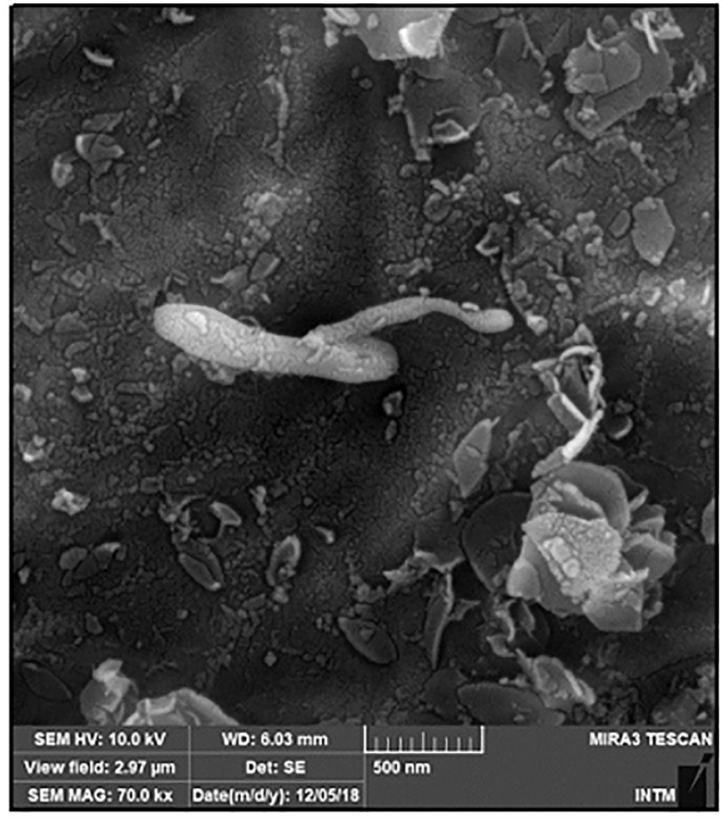

(a) Presence of bacterial cell

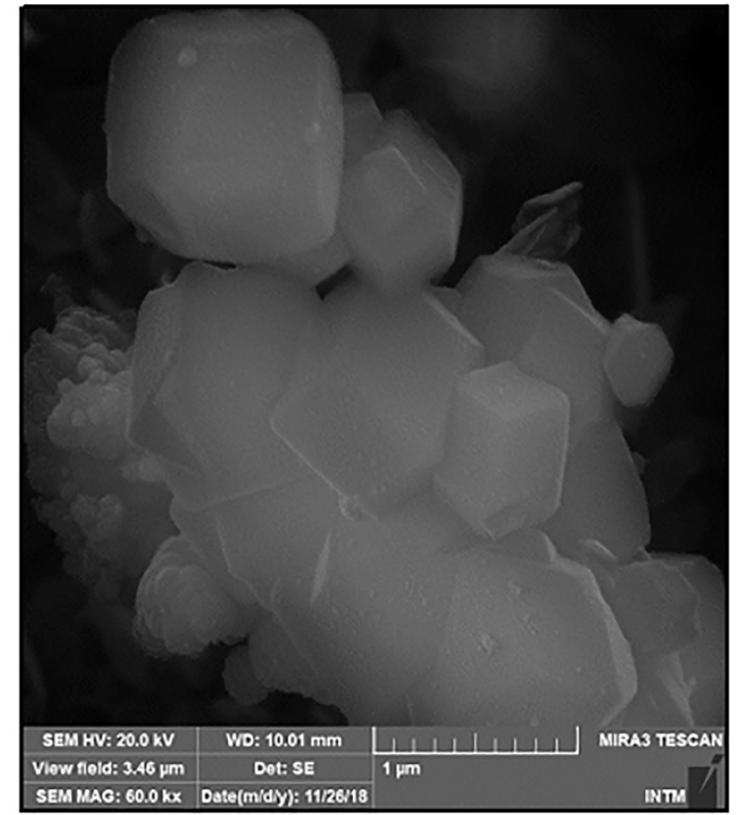

(b) Corrosion product

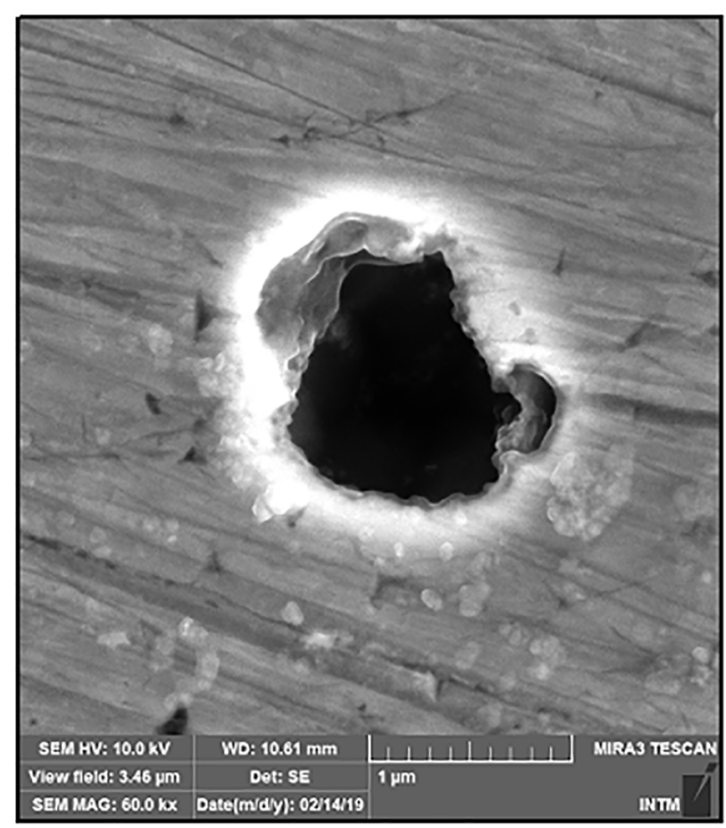

(c) Localized corrosion

Figure 5. Micrographs of ASTM A131 grade A36 carbon steel.

48h, 1 week, 2 weeks, 3 weeks and 4 weeks, compared to the standard analysis result.

As seen in Fig. 7a, the decrease in the diameter of the semicircles of the Nyquist Diagram occurred due to the increase of the immersion time in oil. This behavior can be attributed to the performance of microorganisms in the process of biodegradation of fuel, with the formation and release of compounds that can make the medium more corrosive.
According to Deyab et al. ${ }^{17}$, the increase in storage time leads to a decrease of the capacitive arcs, this is, it reduces the resistance to charge transfer. The researchers observed that the capacitance on the double layer increased because of the increase in the exposure time of the oil in contact with saline water.

The analyzis in the Bode Phase and Bode Modulus Diagrams (Fig. 7b), in the high frequency region, showed 


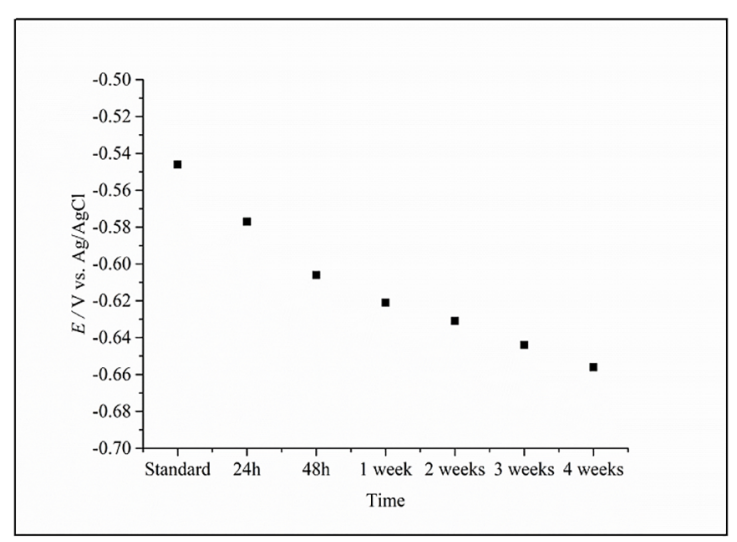

Figure 6. Punctual values of the open circuit potentials for ASTM A 131 grade A36 carbon steel immersed in diesel oil S10 over 30 days.

variations in the impedance values, indicating that there was a change in the resistance value of the solution in function of the immersion time. This behavior confirmed that there is an influence on the composition of the fluids (oil/water) in contact with each other, thus altering the conductivity of the system.

A decrease in the value of the impedance modulus was observed in the low frequency region in function of the increase in the exposure time. Higher impedance modulus value was observed for the standard analysis. In this case, the oil acted as a protective barrier, difficulting the access of the electrolyte, which contributed to increase the polarization resistance of the system.

For the higher immersion times, the reduction in the impedance modulus can be attributed to the process of biodegradation of the fuel, which makes the medium increasingly corrosive.
It is believed that, with the biodegradation process, the oil loses this protective barrier character, facilitating the permeation of the electrolyte. The contact of saline water and the presence of aggressive compounds from the oil biodegradation process can lead to corrosion ${ }^{18,19}$.

Polarization analyses were performed to monitor the corrosion processes in function of fuel biodegradation. Fig. 8, shows the polarization curves (anodic and cathodic) obtained for ASTM A 131 grade A36 carbon steel exposed to diesel oil $\mathrm{S} 10$ contaminated with saline water for a period of 30 days. It was observed that there was a reduction in the corrosion potential $\left(\mathrm{E}_{\text {corr }}\right)$ in function of the storage time of the fuel for carbon steel and consequently, the increase in the corrosion current density $\left(\mathrm{i}_{\text {corr }}\right)$.

The behavior of these parameters is related to the biodegradation of the fuel, which happened gradually with

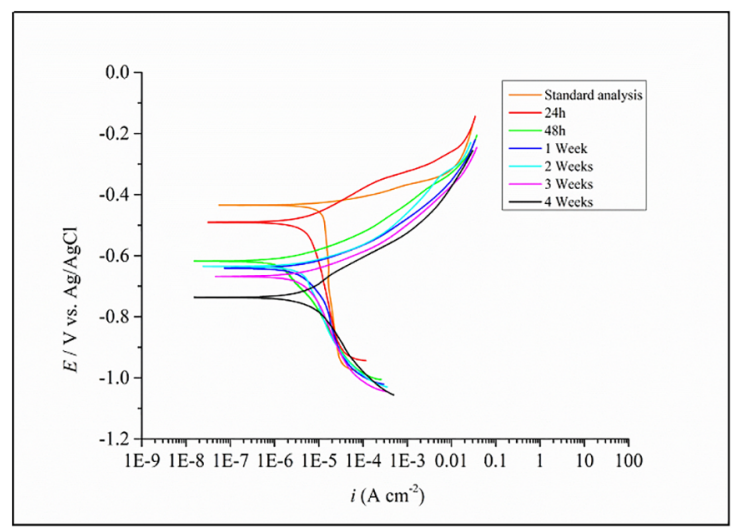

Figure 8. Potentiodynamic polarization curves for ASTM A 131 grade A36 carbon steel immersed in diesel oil S10 over 30 days.

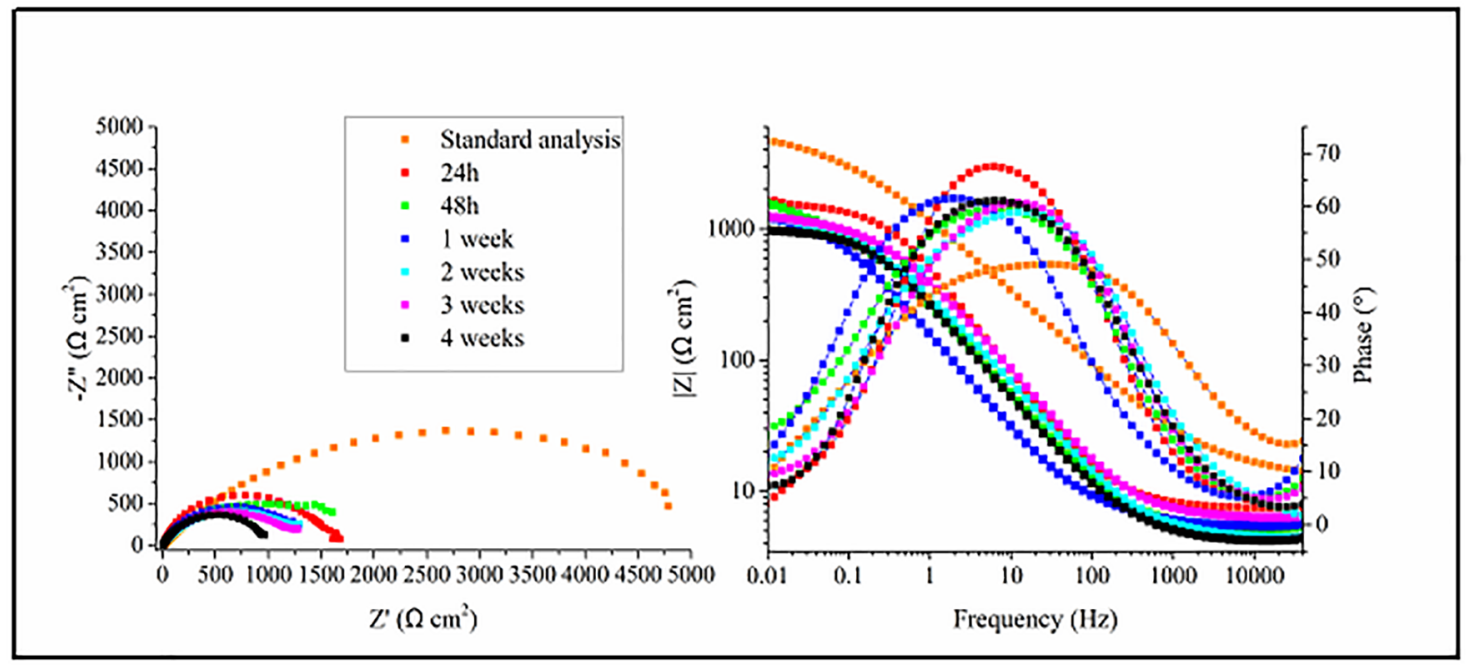

(a) Nyquist diagrams

(b) Bode Phase and Bode Modulus diagrams

Figure 7. Study S2: (a) Nyquist diagrams and (b) Bode Phase and Bode Modulus diagrams plotted for carbon steel exposed in diesel oil S10 contaminated with saline water for 30 days. 
the immersion time. Possibly, reactions on the metallic surface in contact with the fuel occurred, leading to the formation of a protective film, which lost its efficiency over time ${ }^{20}$.

Fazal et al. ${ }^{21}$, when studying the influence of biodiesel instability and corrosivity and its mixture with diesel, observed that biodiesel, because of its self-oxidative nature, is comparatively more corrosive than petroleum diesel and may alter the properties of the fuel. The results showed that the corrosion rate of the metal surface immersed in biodiesel intensified as the immersion time increased.

Deyab and Keera ${ }^{22}$ had similar results when they studied corrosion and biocorrosion processes in carbon steel in contact with biodiesel contaminated with water for 6 months. They observed that the immersion time played a role in the biodegradation of the biofuel. The results in the polarization curves showed a reduction in corrosion potentials and an increase in corrosion current density. Based on these responses, it was possible to observe that the corrosion rates of the carbon steel increased, indicating a corrosive process more pronounced over time.

Pullen and Saeed ${ }^{23}$ and Wang et al. ${ }^{24}$ noticed that the electrochemical corrosion of carbon steel occurred when the fuel was exposed to sea water. They observed that there is no way to control the corrosion and biocorrosion processes during the handling, storage, transport and distribution of fuels due to the microbiota in the fluids.

Matos ${ }^{7}$ studying the corrosion and biocorrosion in ferrous alloys in diesel and biodiesel, observed with the naked eye there was a change of coloration in the fuels during the 10 days of carbon steel immersion. This indicates that changes occurred in the fuel properties due to reactions occurring between the fuel and the metal or due to self-oxidation processes. In addition, the anodic potentiodynamic polarization analysis showed that there was a shift to more negative values in the corrosion potential observed for the samples immersed in biodiesel, suggesting that the immersion decreased the resistance to the polarization on the metal surface.

\section{Conclusion}

The electrochemical impedance spectroscopy analysis of the ASTM A 131 grade A36 carbon steel immersed in a biphasic system, diesel oil S10 / saline water in $\mathrm{NaCl} 3.5$ wt.\%, with the samples immersed in aqueous solution, showed that there was a reduction of the capacitive arcs, due to the occurrence of corrosion and biofilm adherence on the metal surface, in function of the exposure time.

The electrochemical measurements indicated that the corrosion products films display protective characteristics, acting as a barrier to the diffusion of the ionic species. The two layers of formed deposits showed distinct compactness and porosity in the period of 30 days.

The analysis in the Nyquist and Bode Diagrams in the high frequency region showed very low and close impedance values, indicating that there was little change in the resistance value of the solution in function of the immersion time. In the low frequency region, the behavior of the material was evaluated, in which the impedance modulus decreased with the increased electrolyte exposure time. This behavior may be associated with the morphological nature of the film deposited on the metal surface.

SEM images showed the presence of microorganisms in the form of rods, besides the corrosion products formed on the metal surface, also being observed localized corrosion, for the samples immersed in aqueous solution.

The electrochemical analyzes of study S2 showed that it was possible to observe responses from indirect studies to obtain satisfactory results regarding the electrochemical tests. From the OCP analysis, it was observed that diesel oil S10 without saline has a higher corrosion potential compared to saline contaminated oil for 30 days, suggesting a biodegradation process of the fuel.

Electrochemical impedance spectroscopy analyzes showed that there was a decrease in semicircle diameter in the Nyquist diagram, which is associated with increased oil storage time. This behavior can be attributed to the performance of microorganisms in the fuel biodegradation process, with the formation and release of compounds that can make the environment more corrosive. The analyzes in the high frequency regions showed variations in the impedance values, indicating that there was a change in the solution resistance value as a function of the immersion time. This behavior confirmed that there is influence on the composition of fluids (oil / water) in contact by changing the conductivity of the system.

The polarization curves showed that reactions occurred on the metal surface in contact with the fuel. Initially, a protective film formed, which lost its efficiency over time, leading to higher values in current density and potential reduction. Thus, it was observed that there was biodegradation of diesel oil S10 as the storage time of the fuel in contact with saline water increased.

\section{Acknowledgements}

We are grateful for the support to the develop this research that we received from the Federal University of Pernambuco, Fundação de Amparo à Ciência e Tecnologia de Pernambuco (FACEPE), Coordenação de Aperfeiçoamento de Pessoal de Nível Superior (CAPES), Conselho Nacional de Desenvolvimento Científico e Tecnológico (CNPq) and PETROBRAS.

\section{References}

1. Aktas DF, Sorrell KR, Duncan KE, Wawrik B, Callaghan AV, Suflita JM. Anaerobic hydrocarbon biodegradation and biocorrosion of carbon steel in marine environments: the impact of different 
ultra low sulfur diesels and bioaugmentation. International Biodeterioration and Biodegradation. 2017;118:45-56.

2. Song X, Yang Y, Yu D, Lan G, Wang Z, Mou X. Studies on the impact of fluid flow on the microbial corrosion behavior of product oil pipelines. Journal of Petroleum Science and Engineering. 2016;146:803-812.

3. Kovács A, Tóth J, Isaák GY, Keresztényi I. Aspects of storage and corrosion characteristics of biodiesel. Fuel Processing Technology. 2015;134:59-64.

4. Frazão DM, Melo IR, Montoya M, Urtiga Filho SL. Biocorrosion on surface of ASTM A283 Carbon steel, exposed in diesel S10 and tap water. Materials Reasearch. 2017;20(Suppl 2):808-818.

5. Lee JS, Ray RI, Little BJ. Corrosion-related consequences of biodiesel in contact with natural seawater. NACE International. 2010;1:1-19.

6. Tan YJ. Experimental methods designed for measuring corrosion in highly resistive and inhomogeneous media. Corrosion Science. 2011;53:1145-1155.

7. Matos LAC. Estudo da corrosão de ligas ferrosas em diesel e biodiesel [dissertação]. Guarapuava (PR): Universidade Estadual do Centro-Oeste; 2013.

8. Wolynec S. Técnicas eletroquímicas em corrosão. São Paulo: Editora da Universidade São Paulo; 2003.

9. Lopes NF. Corrosão de aços utilizados na indústria de petróleo por CO2 sob pressão, temperatura e meio corrosivo similar ao encontrado em reservatórios do pré-sal [tese]. Porto Alegre (RS): Pontifícia Universidade Católica do Rio Grande do Sul - Instituto Superior Técnico; 2017.

10. Vieira MRS. Estudo dos processos de corrosão e biocorrosão causados por fluidos da indústria de petróleo [tese]. Recife (PE): Universidade Federal de Pernambuco - Pós-Graduação em Engenharia Mecânica; 2013.

11. Zhang GA, Gheng YF. Electrochemical corrosion X65 pipe in oil/water emulsion. Corrosion Science. 2009;51:901-907.

12. Tribollet B, Orazem ME. Electrochemical impedance spectroscopy. New Jersey: John Wiley \& Sons; 2008.

13. Gentil V. Corrosion. $6^{\text {th }}$ ed. Rio de Janeiro: LTC; 2011.
14. Beimeng Q, Beijia W, Chenguang W, Yixing Y. Electrochemical behavior of cast iron in the presence of bacteria in water distribution systems. International Journal of Electrochemical Science. 2013;8:1813-1821.

15. Maruthamuthu S, Kumart BD, Ramachandrant S, Anandkumar B, Palanichamys S, Chandrasekaran M, et al. Microbial corrosion in petroleum product transporting pipelines. Industrial and Engineering Chemistry Research. 2011;50(13):8006-8015.

16. Jones DA, Amy PS. A thermodynamic interpretation of microbiologically influenced. Corrosion. 2002;58:638-645.

17. Deyab MA, Ouarzal R, Lachkar M, El Bali B, Essehli R. Phosphites compound: novel corrosion inhibitor for radioactive waste container (carbono steel) in simulated Callovo-Oxfordian $\left(\mathrm{CO}_{\mathrm{x}}\right)$ groundwater. Journal of Molecular Liquids. 2016;219:994999.

18. Deyab MA. Corrosion inhibition of aluminum in biodiesel by ethanol extracts of Rosemary leaves. Cairo, Egypt. Journal of the Taiwan Institute of Chemical Engineers. 2016;58:536-541.

19. Deyab MA, Abd El-Rehim SS. Effect of succinic acido on carbono steel corrosion in produced water of crude oil. Journal of the Taiwan Institute of Chemical Engineers. 2014;45(3):10651072.

20. Pattamaprom C, Pakdee W, Ngamjaroen S. Storage degradation of palm-derived biodiesel: its effects on chemical properties and engine performance. Renewable Energy. 2012;37(1):412-418.

21. Fazal MA, Suhaila NR, Haseeb ASMA, Rubaiee S, Al-Zahrani A. Influence of copper on the instability and corrosiveness of palm biodiesel and its blends: an assessment on biodiesel sustainability. Journal of Cleaner Production. 2018;171:1407-1414.

22. Deyab MA, Keera ST. On corrosion and corrosion inhibition of carbon steel in stored biodiesel: electrochemical (AC e DC) studies. Journal of the Taiwan Institute of Chemical Engineers. 2016;68:187-191.

23. Pullen J, Saeed K. An overview of biodiesel oxidation stability. Renewable and Sustainable Energy Reviews. 2012;16:5924-5950.

24. Wang W, Jenkins PE, Ren ZY. Electrochemical corrosion of carbon steel exposed to biodiesel/simulated seawater mixture. Corrosion Science. 2012;57:215-219. 